\title{
COPING WITH THE COVID19 PANDEMIC IN A HEMATOLOGY, TRANSPLANTATION AND CELL THERAPY UNIT IN SOUTHERN BRAZIL
}

\author{
OPINION LETTER
}

\author{
Alessandra Paz- Chief of Hematology and stem cell transplantation department, of Porto Alegre \\ Clinicas Hospital- RS
}

Correpondence to: alepaz@hcpa.edu.br

We started 2020 with perspectives that quickly changed in March when the SARS-Cov-2 pandemic started in Brazil. Our center has a unit, called the Protected Environment with 30 beds with HEPA filters where malignant disease, autologous and allogeneic transplants are performed. In March 2020, the contingency plan designed since January to deal with COVID 19 pandemic of Porto Alegre Clinicas Hospital (HCPA) began highly restricting visits, consultations and elective procedures.

Our challenge was to maintain the best care for our patients and healthcare professional's safety. We suspend all visits and reduce relative patients' companies to only essential. Our team was already one with the highest percentage of hand washing in the hospital, intensified infection control measures and implemented new individual protection equipment surgical masks and face shields. We started a new way to inform family members using digital platforms and improved the Wi-Fi network inside the unit to maintain patient external contact and reduce their loneliness. All Professional meetings and rounds became virtual..[1,2,3]

When the first cases started in Porto Alegre, we had already implemented and validated the performance of the PCR for SARS-COV-2, with result until 24 hours. So, we could organize the flow of patients for hospitalizations avoiding admissions of Covid asymptomatic patients. HealthCare's with any symptoms were kept away from work and quickly tested.

We followed the guidance of the Brazilian society of BMT and started to perform only urgent transplants, greatly reducing the number of autologous transplants performed. All patients candidates stem cell transplant were instructed to maintain isolation for 14 days before admission and collected PCR 24 hours before admission. Related and unrelated bone marrow donors underwent clinical screening and PCR testing 24 hours before collection and the marrow was cryopreserved until results what changed our routine marrow infusion and sometime modified the collection from marrow to peripheral Hematopoietic stem cell in order to obtain adequate cellularity. $[1,2,3]$

Despite all the difficulties and challenges the Covid pandemic imposed upon us, we managed to perform 16 Transplants from March to September, between autologous and allogeneic and we had no cases of covid transmission inside deaths related to COVID until now. All patients who had COVID19 or tested positive to SarsCov2 were outpatients, either from the Day Hospital or the outpatient clinic and had complete resolution of the condition.

\section{REFERENCES}

1. https://www.sbtmo.org.br/kcfinder/upload/file/ Recomenda\%C3\%A7\%C3\%B5es\%20para\%20 Manejo\%20da\%20COVID_atualizado\%20 em\%207\%20de\%20julho\%202020.pdf

2. Per Ljungman, Malgorzata Mikulska, Rafael de la Camara, et al. European Society for Blood and Marrow TransplantationThe challenge of COVID-19 and hematopoietic cell transplantation; EBMT recommendations for management of hematopoietic cell transplant recipients, their donors, and patients undergoing CAR T-cell therapy Bone Marrow Transplany 2020 May v, 13 , p. 1-6

3.http://redome.inca.gov.br/posicionamento-redome/ 